\title{
U.S. Fertility Rates and Births Continue to Diminish
}

Kenneth M. Johnson

$\mathrm{N}$ ational Center for Health Statistics data for 2019 show the lowest fertility rates on record and just 3,746,000 births-the fewest since 1985. There were 570,000 fewer births (13 percent) in 2019 than in 2007, just before the Great Recession began to influence births. This decline in births is entirely due to reduced fertility rates among women in their teens and 20s. Fertility rates remained stable or grew slightly among older women. The number of women of prime child-bearing age (20-39) increased by 3.2 million ( 8 percent) between 2007 and 2018. Had pre-recessionary fertility patterns been sustained through 2019, there would have been 6.6 million more births and nearly 3 million more women would have had their first child over the last 11 years. As fertility rates begin to be impacted by the coronavirus pandemic and its economic aftermath, a critical question is: how many of these births will be delayed, and how many will be foregone entirely? This has implications for health care, schools, childrelated businesses, and eventually for the labor force.

\section{ACTUAL BIRTHS COMPARED TO BIRTHS USING PRE-RECESSION BIRTH RATES, 2007 TO 2019}

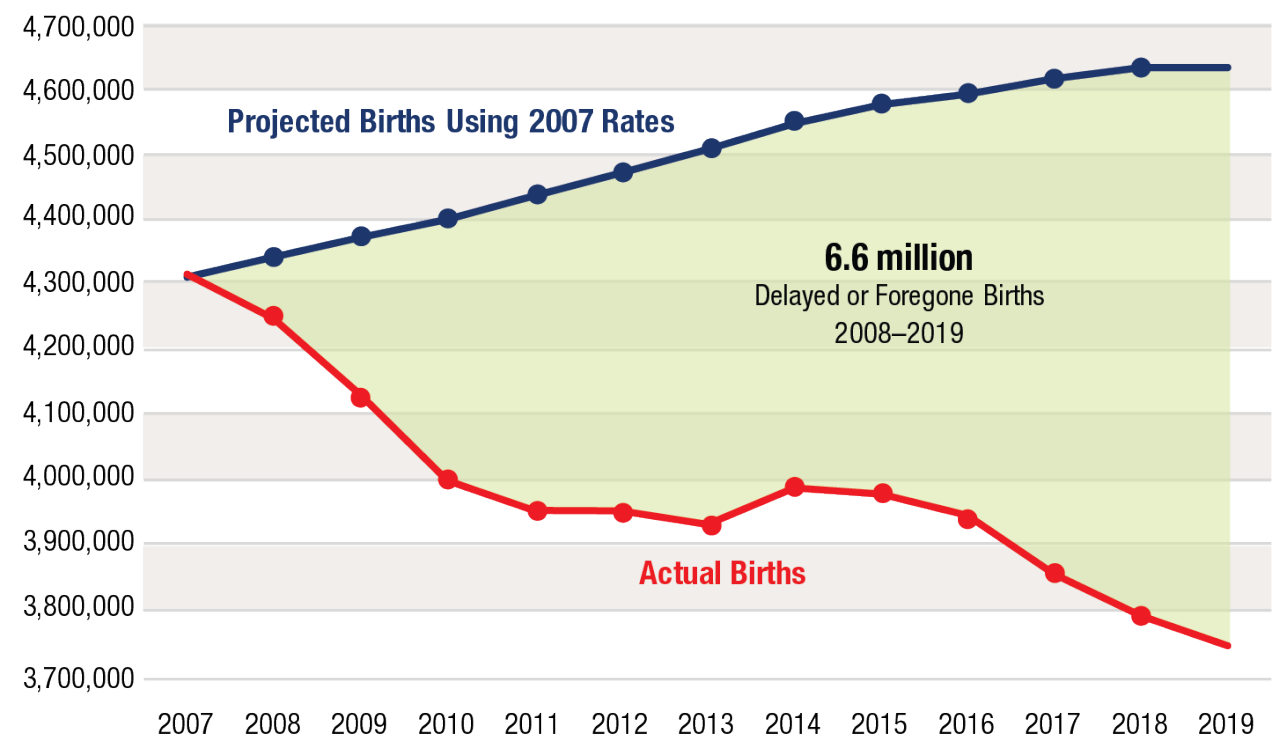

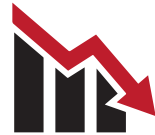

6.6 million fewer births have occurred over the past 11 years than would have been expected given pre-recession fertility rates.

See Related Publications at carsey.unh.edu

- U.S. Fertility Rate Hits Record Low and Births Continue to Diminish (May 2019)

-2.1 Million More Childless U.S. Women Than Anticipated (December 2017)

\section{About the Author \\ Kenneth M. Johnson is senior demographer at the Carsey School of Public Policy, professor of sociology at the University of New Hampshire, and an Andrew Carnegie Fellow. His research was supported by the Carnegie Corporation. The opinions are his and not those of the sponsoring organization.}

Huddleston Hall • 73 Main Street • Durham, NH 03824 carsey.unh.edu • 603.862.2821
TTY USERS: DIAL 7-1-1 OR 1-800-735-2964 (RELAy N.H.) 